\section{PHYSICAL MEASUREMENT IN GAS DYNAMICS AND COMBUSTION}

\section{Physical Measurements in Gas Dynamics and Com- bustion}

Edited by R. W. Ladenburg, B. Lewis, R. N. Pease and H. S. Taylor. (High Speed Aerodynamics and Jet Propulsion-Vol. 9.) Pp. xvi +578. (Princeton, N.J. : Princeton University Press ; London : Oxford University Press, 1955.) 84s. net.

7

HE great advances in aeronautical science have been accompanied by remarkably fast developments in experimental techniques for studying the various aspects of the flow of gases. The first part of this volume, which is the ninth of a series of twelve on high-speed aerodynamics and jet propulsion, deals with methods of measurement of density, pressure, temperature, velocity and state of turbulence. Developments in the usual methods, such as schlieren photography, interferometry, hot-wire anemometry, piezoelectric pressure gauges, temperature measurements from infra-red radiation, and shielded thermocouples, are described. A number of interesting, and sometimes surprising, recent or possible techniques are also examined : these include the use of active nitrogen for following density changes at very low pressure ; the use of ultra-violet or X-ray absorption spectra to measure density ; determination of velocity from the quenching of glow discharges; study of polarization and wave-length distribution of scattered light for mist condensation problems; the use of light reflected at grazing incidence to determine the thickness of a shock wave ; and the determination of the surface temperature of projectiles in flight by coating them with a temperature-sensitive phosphor.

'The second part of the book deals with measurements on combustion gases; this is restricted to physical methods, as another volume, on "Combustion Processes", is in preparation. There are chapters dealing with flame photography, temperature measurements, determination of burning velocity, flame spectroscopy, the use of mass spectra, and analysis of the structure of the flame front. Standard methods are again covered, and some new techniques are discussed; these include developments in the spectrum-line reversal method of temperature measurement to give the temperature of complex flames, and the use of line broadening and Doppler shift to give pressure and gas velocity in rocketmotor flames; spectroscopic determination of effective rotational temperature; and the study of the thick reaction zone of flames at very low pressure.

The sections in the part of the book on gas dynamics tend to be rather short and specialized, so that the effect is like a series of articles in a review journal, such as Reviews of Modern Physics, rather than a unified book. The combustion section, although limited to physical measurements, consists of longer, more comprehensive articles. Dr. E. F. Fiock's on burning velocities is very clear and includes new results ; Dr. F. P. Bundy and Dr. H. M. Strong's is particularly good on the spectroscopic temperature measurements; Dr. W. T. Reid's on flame photography is easy to read but incomplete; Prof. G. H. Dieke gives a good account of developments in photoelectric spectroscopy as applied to flames; and Mr. N. Thomas stresses the value of the new techniques for the detailed understanding of flame structure.
The rapid developments in the many aspects of this field of research made the book necessary. The inevitable time-lag in publication is probably responsible for some omissions; there does not appear to be any mention of quantitative neutral-wedge schlieren photography, or of studies of flame structure from measurements of refractive index made with an inclined slit.

The book comprises twenty-four articles by twenty-two authors. Generally the standard is high, and these articles, at an advanced level, in which so many developments in techniques are discussed, are welcome. Most of the articles are naturally rather specialized, so that most people working in some part of this extensive field will find a few articles of considerable value but also others which cannot easily be read. There is a single collected subjectindex for the whole book, but no author-index. The full references at the end of each article are, of course, valuable.

A. G. GAYDON

\section{MALARIA IN RETROSPECT}

Man's Mastery of Malaria

By Dr. Paul F. Russell. (University of London, Heath Clark Lectures 1953.) Pp. $x v+308+24$ plates. (London: Oxford University Press, 1955.) 25s. net.

$7{ }^{\top} H E$ sixteen years which have elapsed since the start of the Second World War have seen great developments in the control and treatment of malaria. In Ceylon the case-rate per 1,000 living has fallen from 574 in 1940 to 11 in 1953. In Greece the total deaths from malaria in 1942 were 1,856 ; in 1950 there were only 14 deaths from this disease. In Italy, Sicily and Sardinia malaria has been practically eradicated. An illuminating commentary on improvements in treatment is given by the fact that, whereas in Italy, Sicily and Sardinia approximately 300,000 cases resulted in 8,407 deaths in 1919 , in 1945 approximately 400,000 cases resulted in only 386 deaths. Since 1948 there have been no malarial deaths in the Italian Republic. Results of this nature are conducive to a sanguine attitude, and an expert assessment of the position is therefore to be welcomed. Dr. Paul F. Russell devoted his Heath Clark Lectures to this subject in 1953, and in their published form they provide an excellent résumé of the history of the disease and an authoritative discussion of the results of recent measures.

Malaria has a venerable history. Empedocles is supposed to have delivered the city of Selinus from pestilence by diverting two neighbouring streams so that they cleansed the mouth of the river. In Roman times malaria was associated with marshes, and in the Campagna and elsewhere Roman engineers carried out much drainage. Hippocrates gave excellent descriptions of the clinical features of malaria, and also commented on the effect of marshes and stagnant waters in producing enlarged spleens. Despite the warnings given by Celsus, Varro, Columella, Galen and other classical authors, the Pontine Marshes were not successfully drained until the ten-year task which ended in 1940, and successful drainage in Greece is even more recent.

In the case of the malaria parasite there was also an unconscionable lapse of time between the first glimmerings of recognition and the period when practical use could be made of the discovery. The characteristic pigment was seen in spleen and brain 